\title{
Increase in Syntaxin 1B mRNA in Hippocampal and Cortical Circuits During Spatial Learning Reflects a Mechanism of Trans-synaptic Plasticity Involved in Establishing a Memory Trace
} Sabrina Davis, ${ }^{1}$ Jennifer Rodger, ${ }^{2,3}$ Aline Stéphan, ${ }^{1}$ Andrew Hicks, ${ }^{2}$ Jacques Mallet, ${ }^{2}$ and Serge Laroche ${ }^{1,4}$

${ }^{1}$ Laboratoire de Neurobiologie de l'Apprentissage et de la Mémoire

Centre National de la Recherche Scientifique (CNRS)

Unité de Recherche Associée (URA) 1494

Université Paris Sud

91405 Orsay, France

${ }^{2}$ Laboratoire de Génétique Moléculaire de la Neurotransmission et des Processus Neurodégénératifs

Centre National de la Recherche Scientifique

Unité Mixte de Recherche (UMR) 9923

Hôpital de la Pitié Salpêtrière

75013 Paris, France

\section{Abstract}

It has long been proposed that the cellular and molecular mechanisms responsible for LTP may well involve the mechanisms that lead to the type of synaptic modification that occurs during learning. However, it is also known that a single memory trace is encoded in spatially distributed networks; implying that alterations of synaptic strength occur at multiple sites along circuits of connected cells. Recent evidence suggests that regulation of the gene encoding syntaxin 1B, a presynaptic protein involved in exocytosis, plays an important role in the mediation of trans-synaptic LTP, a candidate mechanism for the propagation of plasticity in neural circuits during learning. Using in situ hybridization to measure the mRNA levels at different time points after learning a spatial working or reference memory task, we show that expression of the gene

\footnotetext{
${ }^{3}$ Present address: Department of Zoology, University of Western Australia, Nedlands, Perth, Western Australia 6907

${ }^{4}$ Corresponding author.
}

encoding this protein in the hippocampal and corticoprefrontal circuits increases linearly with performance at a critical window of learning when rats are reaching between $75 \%$ and $100 \%$ of their maximal performance. No changes were observed during the early phases of learning or when rats where overtrained. The correlational analysis indicates that coordinated increases in syntaxin 1B expression occurs in hippocampal circuits during working memory and in more widespread hippocampocortical circuits during reference memory. These results suggest that a form of trans-synaptic plasticity mediated in part by regulation of the expression of syntaxin $1 \mathrm{~B}$ may play an active role in configuring specific spatially distributed circuits during the laying down of memories.

\section{Introduction}

It has long been postulated that memories are represented in the brain as spatiotemporal patterns of cellular activity within distributed networks of cells and that changes take place at the cellular level to store these representations (see Kornorski

LEARNING \& MEMORY 5:375-390 @ 1998 by Cold Spring Harbor Laboratory Press ISSN1072-0502/98 \$5.00

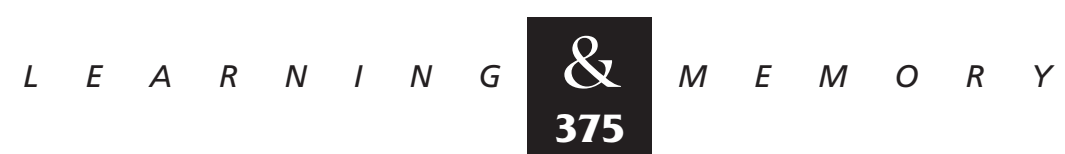


1948; Hebb 1949). The basic assumption is that specific patterns of activity flowing through neural networks strengthen their component synapses, and changes in the weight or strength of these synapses constitutes a mechanism by which preferential coupling among coactivated neurons subserves the formation, storage, and later retrieval of neural representations. The most viable cellular mechanism that results in an enduring form of synaptic modification is long-term potentiation (LTP) (Bliss and Gardner-Medwin 1973; Bliss and Lomo 1973). First demonstrated in the hippocampus, LTP is an extremely persistent form of synaptic strengthening which is studied widely as a potential cellular mechanism subserving learning and memory. It is known now that the initial triggering of LTP in most brain pathways leads to an influx of calcium through the voltage-gated NMDA-receptor channel that induces a rapid and transient activation of several second-messenger cascades and intracellular kinase signaling pathways (for review, see Bliss and Collingridge 1993). It is essential for new proteins to be synthesised for LTP to be stabilized and maintained into the long lasting phases (Otani et al. 1989; Frey and Morris 1997). As a consequence of the initiation of LTP, it is expected that changes at the level of gene expression would take place and there is evidence to suggest that transcription of genes and translation of both newly transcribed and pre-existing mRNAs occur and play important roles in maintaining LTP (Cole et al. 1989; Wisden et al. 1990; Qian et al. 1993; Nguyen et al. 1994; Thomas et al. 1994a; Hicks et al. 1997). Though the fact remains to be clarified: Cellular changes at both the presynaptic and postsynaptic sites are believed to contribute to the expression or maintenance of the increase in synaptic strength in LTP, which eventually lead to the end point; a reorganization of the synapse. Although no single type of morphological or biochemical change has been attributed to the reorganization of the synapse, many possibilities have been either demonstrated or suggested, such as changes in shape or size in dendritic spines and synapses (Van Harreveld and Fifkova 1975; Desmond and Levy 1990), the unmasking of silent synapses (Isaacs et al. 1995), or the growth of new synapses (Edwards 1995). It is more than likely that synaptic modification and anatomical rearrangement of neural circuits such as these may provide the cellular mechanism by which memories could be stored within a neural network of connected cells.

In the hippocampus, experimental evidence suggests that the cellular events underlying LTP are an essential component of the mechanisms of memory formation and, to a certain extent, experiments have shown already that biochemical and morphological changes that occur after the induction of LTP also occur after learning. Examples of these include an increase in the release or the potential to release glutamate (Laroche et al. 1987; Richter-Levin et al. 1995), changes in second messengers (Laroche et al. 1990a) and kinase activity (Bank et al. 1988; Olds et al. 1989; Noguès et al. 1994), increase in receptor sensitivity (Tocco et al. 1991), changes in expression of transcription factors (Tischmeyer et al. 1990; Bertraina and Destrade 1995; Hess et al. 1995), or changes in effector genes (Davis et al. 1996). Finally, there is morphological evidence for synaptic reorganization after learning (Moser et al. 1994; Rusakov et al. 1997) or when rodents have been reared in an enriched environment (Sirevaag and Greenough 1988).

Although these data suggest a mechanism for the encoding of information and the processing of memories, it is known that memories are not encoded at a single synapse. Evidence from several sources, including neuropsychological findings, cerebral imagery, and lesion and cell recording studies converge to suggest that memories are encoded in distributed networks. Early studies of the firing pattern of cells during learning (e.g., Olds et al. 1972) as well as more recent data derived from multiple-array electrodes, have suggested that ensembles of cells in local circuits in the hippocampus (Wilson and McNaughton 1993; Deadwyler et al. 1996) or in cortical regions (Kreiter and Singer 1996) engage in synchronous firing in response to particular stimuli or during certain types of learning. In addition, physiological data have shown that certain naturally occurring frequencies of synchronized cell firing may subserve the processing of information or encode memories through the hippocampal circuitry during a period of consolidation (Chrobak and Buzsaki 1996) or that the firing of cell assemblies in spatially separate structures induced by some form of behavioral activity can be synchronized to fire in a temporally linked manner by specific oscillations (Nicolelis et al. 1995; Murthy and Fetz 1996). These data suggest that spatially distributed cell assemblies together encode information that lead to the formation of memories. In addition, they imply the need for changes in synaptic strength to occur at many synaptic sites along a distributed neural circuit, as illustrated in several neurobiological models of

$$
\text { n...... }
$$


memory (Hebb 1949; Wickelgren 1979; Bloch and Laroche 1984; McNaughton and Morris 1987).

Trans-synaptic LTP is a candidate mechanism for the propagation of long-term changes in synaptic strength within a network. To date, there is very little empirical evidence to demonstrate trans-synaptic LTP, as LTP is induced routinely and measured at a single synaptic connection. Berger and colleagues, however, have shown that induction of LTP at the first synaptic connection in the hippocampus, the perforant path to dentate gyrus synapses, results in a subsequent induction of LTP at the next connection, the mossy fiber-CA3 synapse (Yeckel and Berger 1990). These data suggest that initiation of plasticity at one synapse can, in fact, modify the connections downstream from it, or in other words, propagate plasticity through a circuit.

We have investigated potential molecular mechanisms of synaptic plasticity, and have shown that genes encoding certain serine/threonine kinases and NMDA and mGluRs receptor subunits are upregulated locally in the postsynaptic neurons (Thomas et al. 1994a,b, 1996). These changes are likely to be implicated in the maintenance of LTP and the reorganization of synaptic connections at the site of LTP induction. However, in the postsynaptic neurons, we have also established that the expression of certain genes encoding presynaptic vesicle proteins are increased (Smirnova et al. 1993; Hicks et al. 1997). One of these proteins, syntaxin $1 \mathrm{~B}$, has been shown to be important for the activity-dependent release of neurotransmitter. It is located in the synaptic membrane and through its interaction with SNAP25 and synaptobrevin it is believed to form a core complex that forms an anchor for a cascade of events to make already docked vesicles competent for fusion with the membrane (Broadie et al. 1995; Südhof 1995). It also lies in close proximity to calcium channels and through its interaction with synaptotagmin, which is modified by changes in the local concentration of calcium, it may stimulate fusion to the membrane and exocytosis (Chapman et al. 1995; Li et al. 1995).

We have shown that the mRNA encoding syntaxin $1 \mathrm{~B}$ is upregulated in the granule cell bodies of the dentate gyrus following the induction of LTP at perforant path-dentate gyrus synapses. As the mRNA encoding this presynaptic vesicle protein is increased postsynaptically, these data have suggested the involvement of transcription of the gene encoding syntaxin $1 \mathrm{~B}$ and translation of the mRNA in a molecular mechanism mediating trans-synaptic plasticity (Hicks et al. 1997; Davis and Laroche 1998), where induction of LTP at the input stage of the hippocampus would propagate a signal beyond this synaptic connection to induce LTP at the mossy fiber synapse. Further evidence for this hypothesis was obtained by showing that several hours after the increase in the mRNA, the actual protein level was increased at the next synaptic connection in the mossy-fiber terminal zone (Hicks et al. 1997). Moreover, quantification of the protein using a mossy fiber-specific synaptosomal preparation, showed that the increase in syntaxin $1 \mathrm{~B}$ content correlates with a functional increase in the release of glutamate in the same mossy-fiber terminals (Helme-Guizon et al. 1998). The increases in mRNA levels, in protein content, and in glutamate release were all LTP-dependent as they were not expressed if LTP was blocked with an NMDA-receptor antagonist. These data suggest that the regulation of syntaxin $1 \mathrm{~B}$ may play an important role in the mediation of trans-synaptic plasticity, and therefore may also be important for propagating plasticity along a network of connected neurons in the laying down of memories.

Proof that synaptic changes occur at successive, spatially separated regions within a distributed circuit of connected neurons during learning is scarce, but examples in support of this hypothesis may be found in experiments showing concomitant increases in the capacity for releasing neurotransmitter at synapses of the three hippocampal subregions during learning (Laroche et al. $1987,1990 a)$, or in the activation of immediateearly genes in various circuits and structures during learning tasks (Beck and Fibiger 1995; Bertraina and Destrade 1995; Hess et al. 1997). In the latter cases, however, it is not always easy to link the observed changes with specific mechanisms of synaptic plasticity. In a recent study, we have used quantification of the expression of syntaxin $1 \mathrm{~B}$ as a marker of trans-synaptic plasticity to examine whether this mechanism is activated during learning and to map regions and circuits in the brain that express it. We have demonstrated that the mRNA encoding syntaxin $1 \mathrm{~B}$ is increased in a taskand structure-dependent manner in rats trained to criteria in a spatial reference or working memory task (Davis et al. 1996). In the rats learning a reference memory task, we found that the expression of syntaxin $1 \mathrm{~B}$ was increased in a region of the prefrontal cortex, the prelimbic area, that receives a monosynaptic input from the hippocampus. In

$$
\begin{array}{llllllllllllllll}
\hline & E & A & R & N & I & N & G & \boldsymbol{Q} \\
\mathbf{3 7 7} & M & E & M & O & R & Y
\end{array}
$$


contrast, rats learning a working memory task showed an increase in the expression of syntaxin $1 \mathrm{~B}$ in the three subregions of the hippocampus, the dentate gyrus and areas CA3 and CA1, but not in the prefrontal cortex. Furthermore, we have also shown that the increase in syntaxin $1 \mathrm{~B}$, is specific to certain types of learning as it is not increased in the hippocampus, or the amygdala during a contextual fear-conditioning task (Davis and Laroche 1998). Thus, these results strongly suggest a role for the regulation in the expression of syntaxin 1B in specific neural networks during learning and a role for trans-synaptic plasticity in these networks in the establishment of memory traces. At the same time, however, they also raise other important questions relating to the dynamics of this mechanism and exactly which aspects during the learning process that the increase in expression of syntaxin 1B is involved in. For example, we do not know whether the increase in the expression of syntaxin occurs at the end of each learning session or only when rats have reached a certain level of learning; how the task and structure-specific increases in expression of syntaxin relate to learning performance; or whether there is a differential increase in these regions at different time points during the evolution of learning.

In an attempt to address these questions, we have now generated data from rats subjected to different levels of training in either the spatial reference or working memory task. We have selected three time points during the course of training -2 , 6 , and 14 days - the latter being considered overtraining, anticipating that in each group rats would show different rates of learning and levels of performance.

\section{Materials and Methods}

\section{EXPERIMENTAL PROCEDURES}

The procedure used in this experiment was essentially the same as that described by Davis et al. (1996). In brief, 50 adult male Sprague-Dawley rats, weighing between 300 and 350 grams, were used. They were trained in either a spatial-reference memory task $(n=15)$, a spatial-working memory task $(n=15)$, or a motor-control task $(n=15)$. Five rats in each group were killed after either 2, 6, or 14 days of training. An additional five rats were used as a caged naive control group. The rationale for using these three time points was that individual rats would naturally show a different rate of learning and a different level of performance and this could be compared with the results from animals killed exactly when they were reaching learning criterion independent of the number of training sessions (see Davis et al. 1996).

\section{BEHAVIORAL TESTING}

All testing was carried out on an eight-arm radial maze, with the arms radiating from a central start platform. At the end of each arm was a plastic food cup, into which a single noyes pellet was placed. The maze stood $70 \mathrm{~cm}$ above the floor and was maintained at the same orientation in a room containing several extramaze cues. Following a habituation period to the maze, rats were assigned to either the reference-memory, the workingmemory, or the maze control groups. In the reference-memory group, the same four out of eight arms were baited with food, and rats used the spatial cues in the room to learn their location. In the working-memory group, rats had access to only five of the arms that were selected randomly for each trial and the correct procedure was to visit each arm only once. In the maze control group, all eight arms were baited and as the rat left each arm, food was replaced in it. Rats were given eight trials a day and were sacrificed $2 \mathrm{hr}$ after the last trial on the last day of training. In the reference-memory task, the rats could make two types of errors: reference-memory errors or working-memory errors. They were considered to have made a referencememory error if they entered a nonbaited arm, and a working-memory error if they re-entered a baited arm. In the working-memory group, re-entries into arms already visited were considered errors. At the end of the behavioral experiment, rats were sacrificed by stunning across the chest and decapitation. The brains were removed on ice, frozen, and stored at $-80^{\circ} \mathrm{C}$.

\section{IN SITU HYBRIDIZATION}

In situ hybridization was performed according to standard protocols described previously (see Davis et al. 1996): 14- $\mu$ m-thick coronal sections were postfixed in $4 \%$ paraformaldehyde in phosphate-buffered saline immediately after cutting and were stored at $-80^{\circ} \mathrm{C}$. The probe used was a 45 mer oligonucleotide complementary to syntaxin 1B (Bennet et al. 1992) and was labeled with $\left[\alpha^{35}\right.$ S]deoxyadenosine triphosphate (Amersham)

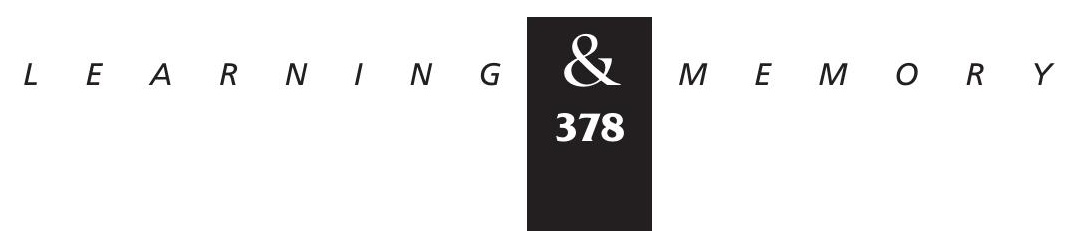


using terminal deoxynucleotidyl transferase (Promega). The specific activity following the labeling was between $1 \times 10^{8}$ and $1 \times 10^{9} \mathrm{cpm} / \mu \mathrm{g}$, and between $1 \times 10^{5}$ and $3 \times 10^{5} \mathrm{cpm}$ were applied to each slice. Hybridization of the slices was carried out in Amersham in situ hybridization buffer supplemented with $40 \%$ formamide, $0.1 \mathrm{M}$ dithiothreitol, $1 \mathrm{mg} / \mathrm{ml}$ poly(A) ${ }^{+}$. Cold controls were carried out to test the probe specificity, hybridizing in the presence of a 50-fold excess of cold probe. The slices were exposed to Amersham $\beta$-max film for between 10 and 14 days.

\section{QUANTIFICATION OF mRNAS}

Quantification for the amount of syntaxin 1B mRNA in the hippocampus and cortical regions of rat brain sections was performed after in situ hybridization on two different image analysing systems (BIOCOM and SAMBA software from Unilog) by two independent researchers to ensure replication of the quantification. Densities of silver grains were measured from resulting autoradiograms and were calculated separately for the following regions: dentate gyrus, CA3, CA1, motor cortical area, parietal cortex, and the prelimbic region of the prefrontal cortex. Between three and six sections per rat per region were analyzed and all values were normalized to values obtained in the corpus callosum on the same brain sections for the hippocampal regions, and in the fimbria fornix for the prefrontal cortex. Statistical analysis, using analysis of variance was carried out on the mean of the optical density measures from each rat, normalized to the naive controls.

\section{Results}

\section{BEHAVIORAL ANALYSES}

Figure 1 shows the learning curves of the rats in the working memory task (Fig. 1A) and the reference memory task (Fig. 1C). Comparison of the figures shows that in both groups, performance increased progressively with training until an asymptotic level is reached after 7-8 days of training. As shown in Figure $1 \mathrm{C}$, rats in the reference memory group made many more reference memory errors than working-memory-type errors. This, demonstrated by a significant interaction between days and error types $(F(2,26)=6.94$; $P<0.01$ ), replicates previous results (Davis et al. 1996) and was expected as the working-memory component of the reference memory task presented here is learned more easily and rapidly than the reference memory component. The rats that were sacrificed after 2 days of training showed very little improvement of performance in either of the tasks across these 2 days. For rats trained for 6 or 14 days, however, individual variation in the amount and rate of learning across animals in each task was increased. We therefore quantified the animal's performance in the radial maze by normalizing each individual rats' daily performance to the maximum number of errors it made during training. Thus, for each individual rat the maximum number of errors is equivalent to $0 \%$ learning and no errors is equivalent to $100 \%$ learning. The resulting curves expressing the percent learning achieved each day in the working and reference memory tasks, where the calculation is based on reference memory errors, are represented in Figure $1, \mathrm{~B}$ and $\mathrm{D}$, respectively. The curve fit for the learning performance is more steep for the rats learning the reference memory task. In both groups, however, the group mean level of $85 \%$ learning ( \pm 1 s.E.M.) was reached on day 7 , suggesting that both tasks were learned in approximately the same number of training sessions. This analysis allowed us to correlate the level of expression of syntaxin $1 \mathrm{~B}$ in the different structures with individual quantitative behavioral data, expressed as the actual percent of learning achieved at the time of sacrifice, rather than with the number of training sessions. To eliminate erratic variation in performance, an individual rat was considered to have learned the task when its performance was $\geqslant 85 \%$ level for two consecutive sessions. When this criteria was not reached, the actual level of performance was used for the correlational analysis, whereas in rats that had passed the criteria, the number of extra training sessions to which they were submitted before sacrifice equates to the number of days of overtraining. Subgroups were also made, based on the percent learning performance or the number of days of overtraining ( $0 \%-$ $25 \%, 25 \%-50 \%, 50 \%-75 \%, 75 \%-100 \%$ of learning; 1-4 and 4-8 days of overtraining).

\section{EXPRESSION OF SYNTAXIN 1B IN WORKING MEMORY}

Levels of syntaxin 1B expression measured in the hippocampus and prefrontal cortex in rats that had attained different levels of learning or overtraining are shown with the data from the motor

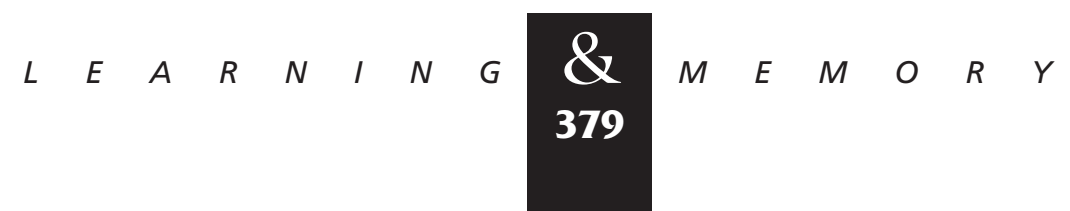




\section{Davis et al.}

A

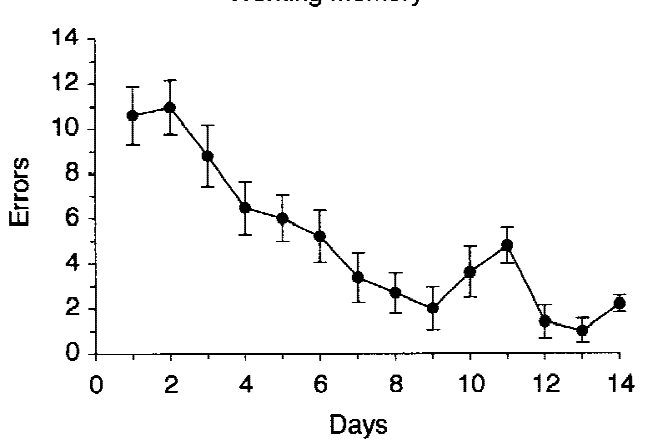

C

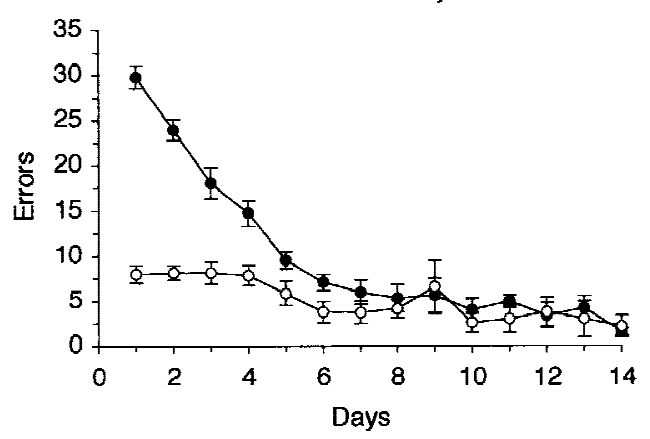

B

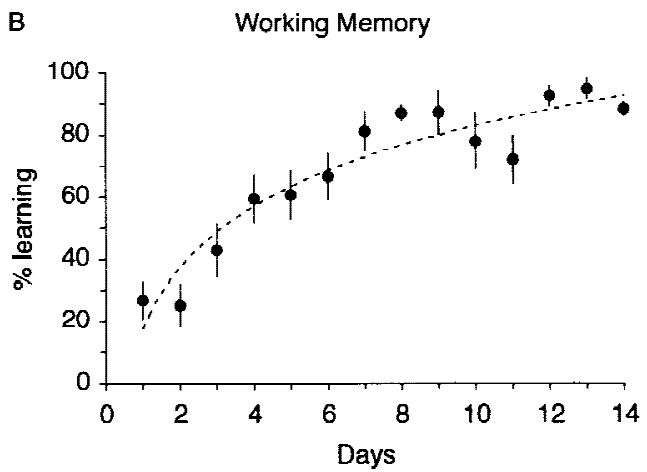

D

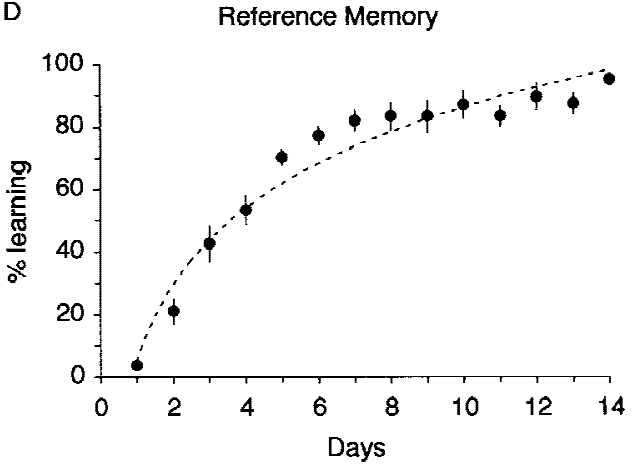

Figure 1: The performance of rats learning a working memory task or a reference memory task. $(A, C)$ Total number of errors made per day by each group. Note that in the reference memory task, both reference $(\mathbf{0})$ and working memory type errors $(O)$ are represented. $(B, D)$ Rats' performance across days based on the percent learning, after normalizing each individual rats' performance to the maximum number of errors it made (see text). A logarithmic curve is fitted to the data points in each group. In the reference memory task, the performance level is based on the reference memory element of the task. The curves represent the pooled data from all rats trained for all different number of sessions.

control group in Figure 2 (A and B). As seen in Figure 2, there was an increase in the expression of syntaxin $1 \mathrm{~B}$ in the three regions of the hippocampus during working memory, when rats had attained between $75 \%$ and $100 \%$ of their maximum learning performance [dentate gyrus: $F(6,23)=$ $6.68 ; P<0.01 ;$ CA3: $F(6,23)=4.67 ; P<0.01 ;$ CA1: $F(6,23)=5.92 ; P<0.01]$. The increase was specific to this level of performance as there were no significant increases in the expression of syntaxin $1 \mathrm{~B}$ in the dentate gyrus and areas CA3 and CA1 in rats at lower levels of learning, or in rats which had passed their maximal level of learning and were overtrained (Fig. 2A). By comparison, there was no significant increase in syntaxin 1B mRNA levels in animals of the motor control group. As shown in Figure $2 \mathrm{~B}$, in the same rats trained in the working memory task, the expression of syntaxin 1B showed a tendency to be elevated in the prefrontal cortex during the early phases of learning. Although the variability was higher than that in the hippocampus, the level of expression in the prefrontal cortex was significantly greater when compared with the naive group. This increase in expression, however, was only elevated in rats that had reached between $0 \%$ and $50 \%$ of their learning capacity $[F(2,12)=3.99 ; P<0.05]$. No change was seen in the prefrontal cortex in the motor controls (Fig. 2B). In addition, there was no apparent change in syntaxin 1B mRNA at any level of learning or overtraining in the parietal $[F(6,23)=2.05$; $P>0.05]$ or motor cortices $[F(6,23)=1.69$; $P>0.05$; data not shown].

The similarity in the increase in syntaxin 1B expression in the three hippocampal subregions and the difference between hippocampus and prefrontal cortex was further estimated by a correlational analysis of the levels of increased expression in the different brain areas measured in individual rats. As shown in Figure 3, there was a very strong correlation in the percent change in syntaxin $1 \mathrm{~B}$ expression between the dentate gyrus and CA3 
A

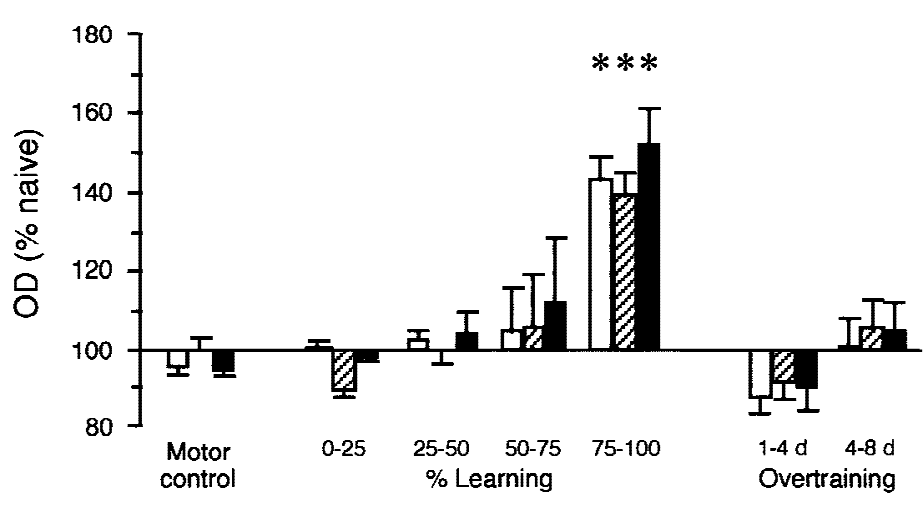

B

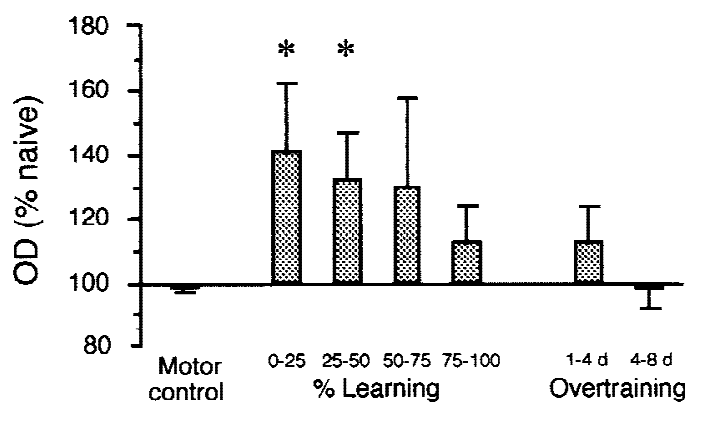

Figure 2: Changes in expression of syntaxin 1B in the hippocampal regions $(A)$ and the prelimbic region of the prefrontal cortex $(B)$ during the working memory task. Optical densities (OD) are normalized to the naive controls $(100 \%)$ and are represented in bins of percent learning or bins of overtraining. The levels of expression of syntaxin $1 \mathrm{~B}$ were significantly elevated in the hippocampus when rats had reached between $75 \%$ and $100 \%$ of the learning performance $(A)$. (Open bars) Dentate gyrus; (hatched bars) CA3; (solid bars) CA1. In the prelimbic region of the prefrontal cortex, syntaxin 1B mRNA levels were elevated in the early stages of learning between 0 and $50 \%$ of the maximum learning performance $(B)$. Note there is no change in the expression levels of syntaxin when rats are overtrained. Included in each graph is the level of expression of syntaxin 1B measured in the same regions in the motor control group. $\left({ }^{*}\right)$ Syntaxin expression was significantly increased compared with naive controls. $(r=0.96 ; P<0.01)$ and between CA3 and CA1 $(r=0.96 ; P<0.01)$, suggesting that the subregions of the hippocampus work in concert with each other (Fig. 3A,B). In contrast, there was no correlation between the increased expression of syntaxin measured in the hippocampus and in the prefrontal cortex $(r=0.06 ; P>0.05)$, suggesting that behaviorally induced changes in syntaxin $1 \mathrm{~B}$ expression show regional independence between the hippocampus and the prefrontal cortex (see Fig. 3C).

To examine the nature of the relationship between performance in working memory and the level of syntaxin 1B expression further, correlations were examined between individual values of syntaxin expression and different parameters of learning. These included percent learning at the time of sacrifice, the rate of learning and the "expected" initial number of errors. The last two parameters were estimated by the slope and $y$-intercept of the linear regression fitted to the individual behavioral data after $\log$ transformation of the number of errors made by each individual rat. The learning parameter determines how fast or slow individual rats learn the task. Data from all individual animals were approximated well by this lin- ear regression. As suggested already by the correlational analysis between hippocampal subregions (Fig. 3A,B), the pattern of results was similar for the dentate gyrus and areas CA3 and CA1 (see also Fig. 1A), thus only the data for the total hippocampus are represented here. As shown in Figure 4A, which describes the relationship with individual levels of performance, there was no clear change in syntaxin expression when rats were below 50\% of their maximum learning performance. As individual rats began to increase their level of learning beyond $50 \%$, the level of syntaxin increased until they had reached $100 \%$. The experimental data were best approximated by fitting a linear regression (Fig. 4A) in which individual rats' performance and the increase in syntaxin expression between the point of 50\% learning and their maximum level showed a very high correlation $(r=0.81 ; P<0.01)$. This was more likely because of their actual performance than their rate of learning as there was no correlation between the estimated learning rate parameter (slope of the linear regression) and the increase in syntaxin expression $(r=0.02 ; P>0.05$; see Fig. 4B). In contrast, there was no apparent relationship between the actual performance and levels of increase in syntaxin ex-

$$
\begin{array}{lllllllllllllll}
L & E & A & R & N & I & N & G & \begin{array}{l}
\boldsymbol{Q} \\
\mathbf{3 8 1}
\end{array} & M & E & M & O & R & Y
\end{array}
$$




\section{Davis et al.}
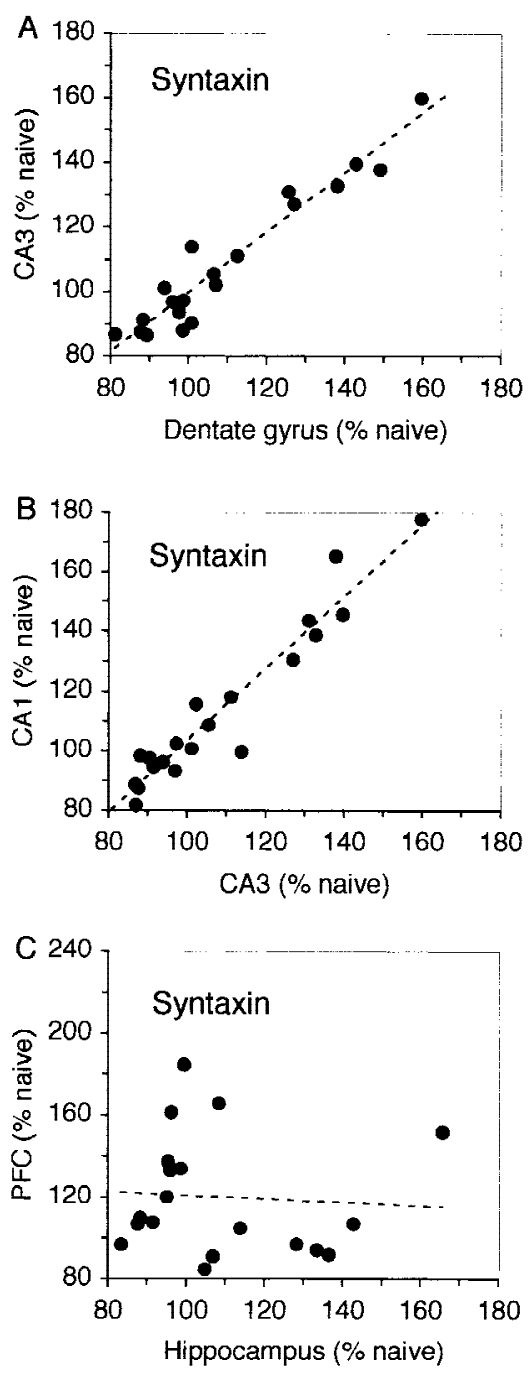

Figure 3: Relationship between the changes in expression of syntaxin $1 \mathrm{~B}$ in the different brain regions in rats that had learned the working memory task. There was a strong correlation between syntaxin expression in the dentate gyrus and CA3 $(A)$, between CA3 and CA1 $(B)$ but not between the whole hippocampus and the prefrontal cortex $(C)$. The graphs represent syntaxin 1B mRNA levels, from individual rats, normalized to naive controls.

pression in the prefrontal cortex $(r=0.45$; $P>0.05$; Fig. $4 \mathrm{C}$ ), but, in contrast to the hippocampus, there was a significant correlation between the levels of syntaxin in the prefrontal cortex and the estimated learning rate parameter $(r=0.77 ; P<0.01$; see Fig. 4D). There was no correlation between the increases in syntaxin expression and the expected initial number of errors, either in the hippocampus, or in the prefrontal cortex $(r=0.31$ and $r=0.397 ; P>0.05$; data not shown). These results suggest that, in the prefrontal cortex, the increase in expression of syntaxin $1 \mathrm{~B}$ is more related to individual learning capacity expressed during training than to the actual amount of training received or the level of performance reached in the working memory task. Thus, rats with a higher rate of learning showed more increase in syntaxin expression in the prefrontal cortex regardless of whether they were before, at, or passed the criteria for learning.

\section{EXPRESSION OF SYNTAXIN 1B IN REFERENCE MEMORY}

A similar analysis of the level of expression of syntaxin $1 \mathrm{~B}$ and learning was performed on the data from rats trained in the reference memory task. Changes in the expression of syntaxin $1 \mathrm{~B}$ during this task present some similarities to the results obtained in working memory but they present some major differences also. In the hippocampus, there was a general increase in the levels of syntaxin mRNA in all three subregions at the point when rats reached between $75 \%$ and $100 \%$ of their maximum performance level (Fig. 5A). This increase, however, was much smaller in amplitude than the increase observed at the same time point during the working memory task (see Fig. 2A for comparison) and, compared to the naive controls, reached statistical significance only in the CA1 region of the hippocampus $[F(5,24)=2.71$; $P<0.05]$. By comparison, and in sharp contrast to what was observed in working memory, the level of syntaxin was elevated greatly in the prefrontal cortex $[F(5,21)=4.84 ; P<0.01]$ when rats had reached between $75 \%$ and $100 \%$ of their learning ability (Fig. 5B). No change in syntaxin 1B expression was observed early in training or when rats were overtrained, either in the hippocampal subregions or in the prefrontal cortex (Fig. 5). There was also no significant change in the levels of syntaxin in the parietal $(F<1)$ and motor $(F<1)$ cortices (data not shown), and no discernible difference in syntaxin expression in any of the brain regions in the motor control group [all hippocampal regions: $F<1$, Fig. 5A; prefrontal cortex: $F(1,162)=3.5 ; P>0.05$, Fig. $5 \mathrm{~B}$; parietal cortex: $F(1,155)=2.97 ; P>0.05$; motor cortex: $F(1,155)$ $=2.62 ; P>0.05]$.

Although the levels of syntaxin 1B mRNA were not increased significantly in the dentate gyrus and CA3 the tendency to be elevated was strong (Fig. $5 A)$ such that there was a significant correlation in

$$
\begin{array}{llllllllllllllll}
L & E & A & R & N & I & N & G & \underset{382}{\mathbf{Z}} & M & E & M & O & R & Y
\end{array}
$$


A

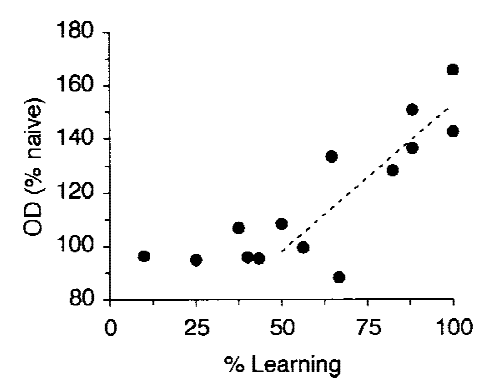

C

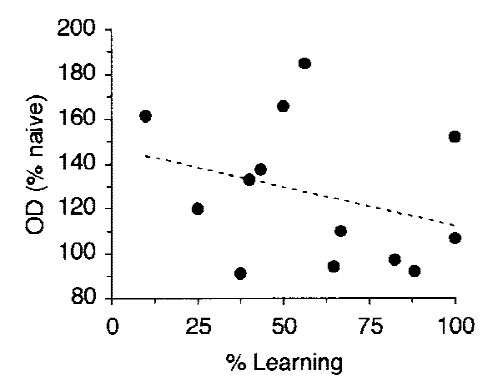

B

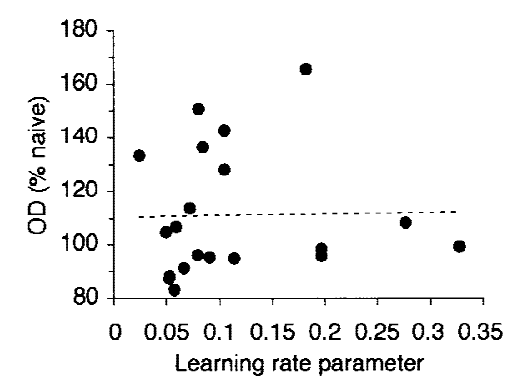

D

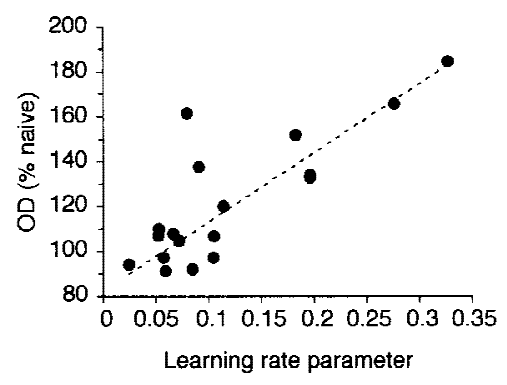

Figure 4: The relationship between learning in the working memory task and expression of syntaxin 1B in the hippocampus $(A, B)$ and in the prefrontal cortex $(C, D)$. In the hippocampus, when rats were between 0 and $50 \%$ of their maximum performance, there was no change in the expression of syntaxin 1B. However, when they had attained more than $50 \%$ of the learning performance, there was a strong linear increase in the levels of expression of syntaxin until rats had reached their maximum level of performance $(A)$. This was related strictly to their performance and not their ability to learn as there was no correlation between syntaxin expression and the learning rate parameter $(B)$. In direct contrast, expression of syntaxin $1 \mathrm{~B}$ in the prefrontal cortex and performance in learning showed no relationship $(C)$ but there was a strong correlation between the increase in syntaxin 1B expression and the learning rate parameter $(D)$. Correlations are based on the values of syntaxin 1B mRNA levels from individual rats, normalized to the naive controls. the percent change in syntaxin expression between the dentate gyrus and CA3 ( $r=0.83$; $P<0.01$; Fig. 6A) and between CA3 and CA1 $(r=0.88 ; P<0.01 ;$ Fig. $6 \mathrm{~B})$. In contrast to what was observed in working memory, however, there was also a strong correlation between the increase in expression of syntaxin $1 \mathrm{~B}$ in the hippocampus and in the prefrontal cortex $(r=0.76 ; P<0.01$; Fig. 6C), indicating that both structures may be acting in concert during the reference memory task.

To determine whether the increase in syntaxin $1 \mathrm{~B}$ expression in the hippocampus and prefrontal cortex was correlated specifically with certain parameters of learning, a similar analysis as that done in working memory was undertaken with the data obtained in the reference memory groups. In the hippocampus, the individual point plot in Figure $7 \mathrm{~A}$ shows that the increase in syntaxin $1 \mathrm{~B}$ expression occurred almost exclusively when rats were at or near the brink of learning. The increased expression between the point of $60 \%$ learning and when the rats had reached their maximum level showed a linear tendency with the amount of learning at the time of sacrifice (Fig. 7A), but the correlation was not strong and did not reach significance $(r=0.60 ; P>0.05)$. The lack of a significant cor- relation is probably because the increase was only observed reliably in rats that were very close to maximum learning. There was no apparent relationship with either the estimated learning rate parameter $(r=0.12 ; P>0.05$; Fig. $7 \mathrm{~B})$ or the expected initial number of errors $(r=0.08 ; P>0.05$; data not shown). Thus, the increase in syntaxin $1 \mathrm{~B}$ expression in reference memory was much smaller than that observed in working memory. The general temporal pattern of increase however was similar to that observed in working memory, with the exception that it was more sharply related to the point at which rats were approaching their maximal level of learning.

The results in the prefrontal cortex were different qualitatively and quantitatively from those observed during the working memory task. In reference memory, there was an increase in the later stages of learning which showed a very sharp linear relationship with the amount of learning $(r=0.69 ; P<0.05$; Fig. $7 \mathrm{C})$, whereas there was no significant correlation with the expected initial number of errors $(r=0.21 ; P>0.05)$ and the correlation with the estimated learning rate parameter (Fig. 7D), although statistically significant $(r=0.49 ; P<0.05)$, was much lower than with the level of performance. Thus, in reference memory,

$$
\begin{array}{llllllllllllllll}
L & E & A & R & N & I & N & G & \mathbf{8} & M & E & M & O & R & Y \\
\mathbf{3 8 3} & & & & & & &
\end{array}
$$




\section{Davis et al.}

Figure 5: Changes in expression of syntaxin $1 \mathrm{~B}$ in the hippocampal regions $(A)$ and the prelimbic region of the prefrontal cortex $(B)$ during the reference memory task. Optical densities (OD) are normalized to the naive controls $(100 \%)$ and are represented in bins of percent learning or bins of overtraining. Although the levels of expression of syntaxin were elevated in the hippocampus when rats had reached between $75 \%$ and $100 \%$ of the learning performance, it only reached a level of significance in the CA1 region $(A)$. (Open bars) Dentate gyrus; (hatched bars) CA3; (solid bars) CA1. In the prelimbic region of the prefrontal cortex, the levels of syntaxin expression at this time was also significantly elevated $(B)$. This increase in syntaxin $1 \mathrm{~B}$ expression had diminished by the time rats began to be overtrained in the task. Included in each graph is the level of expression of syntaxin 1B measured in the same regions in the motor control group. (*) Syntaxin expression was significantly increased compared with naive controls.
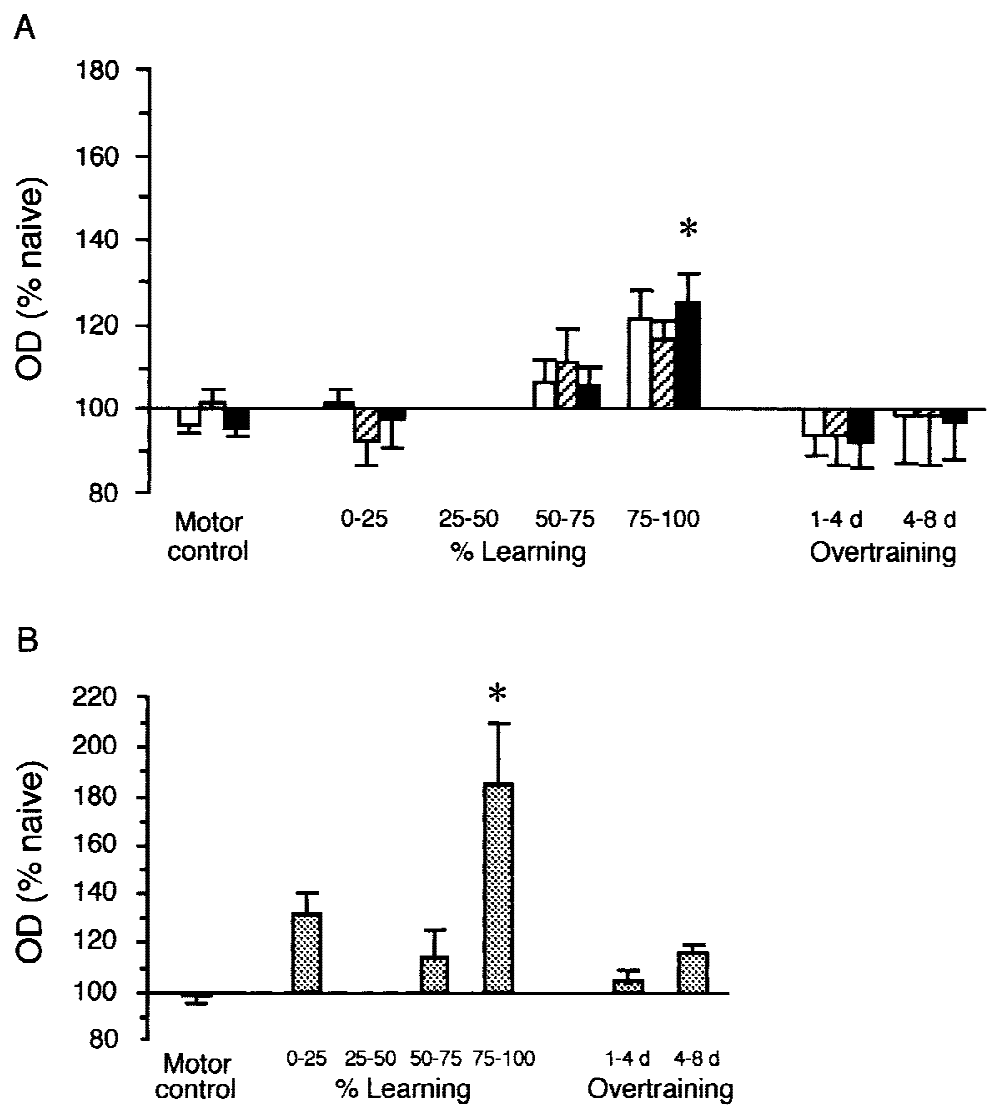

the increase in the expression of syntaxin $1 \mathrm{~B}$ in both the hippocampus and prefrontal cortex is better correlated with the level of performance and associated sharply with the highest level of performance when rats are close to reaching the brink of learning. This similarity reinforces the suggestion that the two structures work in concert at a specific phase of learning the reference memory task.

\section{Discussion}

Based on our previous work in which we have shown that regulation in the expression of syntaxin $1 \mathrm{~B}$ is a candidate mechanism for trans-synaptic plasticity, our aim in these experiments was to use this marker to ascertain whether this form of synaptic modification occurs in the hippocampus and the prefrontal cortex of rats when they have attained different levels of learning in a spatial working memory or a spatial reference memory task. The rationale for measuring syntaxin in the hippocampus and the prelimbic area of the prefrontal cortex was threefold: (1) It has been shown that there is a monosynaptic connection between the two structures (Jay and Witter 1991) and this pathway supports NMDA-receptor-mediated LTP (Laroche et al. 1990b; Mulder et al. 1993; Jay et al. 1995). (2) Changes in synaptic efficacy occur in both structures during the acquisition of certain learning tasks, but the increase in synaptic efficacy is delayed and occurs mostly in overtraining in the hippocampal-prefrontal cortex pathway (Doyère et al. 1993). (3) In our original findings, we showed a differential increase in syntaxin 1B expression in the prefrontal cortex and the hippocampus during a working and a reference memory task (Davis et al. 1996).

The main finding of this experiment is the specificity of the time at which levels of expression of syntaxin were increased in the hippocampus and prefrontal cortex during the course of learning a reference memory task and in the hippocampus during the course of learning a working memory task. Remarkably, the increase in the expression of syntaxin occurred only when rats had reached between $75 \%$ and $100 \%$ of their maximal learning performance, a result in accordance with our previous suggestion that syntaxin expression is in-

$$
\begin{array}{lllllllllllllll}
L & E & A & R & N & I & N & G & \begin{array}{c}
\boldsymbol{Q} \\
\mathbf{3 8 4}
\end{array} & M & E & M & O & R & Y
\end{array}
$$



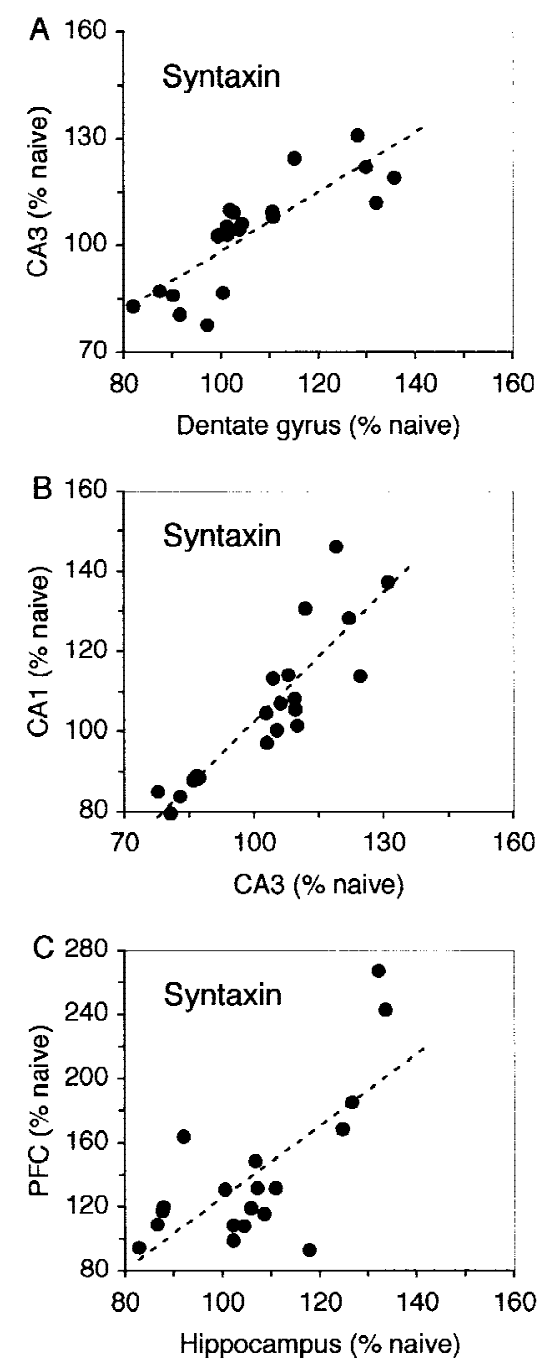

Figure 6: Relationship between the changes in expression of syntaxin $1 \mathrm{~B}$ in the different brain regions in rats that had learned the reference memory task. There was a strong correlation between syntaxin expression in the dentate gyrus and CA3 $(A)$, between CA3 and CA1 $(B)$ and also between the whole hippocampus and the prefrontal cortex $(C)$. The graphs are values of syntaxin 1B expression from individual rats, normalized to naive controls.

creased when rats are on the brink of learning (Davis et al. 1996). In these current experiments, we confirm this specificity by showing there is no change in syntaxin expression in the early phases of learning, with the exception of a change in the prefrontal cortex during working memory, and after this critical period of learning, when rats were overtrained, the increased levels of expression drop rapidly. The strength of these findings lie in the individual correlations between the learning performance and the increase in the expression of syntaxin, in which we were able to determine a more defined window of learning in which syntaxin $1 \mathrm{~B}$ is implicated. In the hippocampus, during the working memory task, as soon as rats had reached $>50 \%$ of their maximal learning performance, they began to show an increase in syntaxin expression and there is a strong linear correlation with the actual level of performance. In the prefrontal cortex and, to a lesser extent, in the hippocampus, a similar linear correlation between the increase in the expression of syntaxin and learning performance was observed during the reference memory task but this was more sharply increased when near maximal performance was reached.

The importance of this result is that syntaxin is not increased at all levels of learning. This suggests that it neither reflects a generalized increase in neural activity that is transiently and possibly repeatedly occurring at the end of each learning session, nor that it is necessary after the learning has been achieved. By the nature of its restricted window of activation, it suggests that syntaxin may be instrumental in helping to stabilize the memory trace for a learned event within a neural circuit. There is to our knowledge very little evidence relating to the involvement of this gene in learning, however, there have been several reports showing the genes encoding the transcription factors c-fos (Beck and Fibiger 1995; Bertaina and Destrade 1995; Hess et al. 1995) and zif-268 (Fordyce et al. 1994) are activated during different forms of learning. Thus, our data find support from these experiments that show part of the neural mechanisms underlying the processing of information during learning requires the activation of the transcriptional machinery. The increase in c-fos during learning has been shown in several regions of the brain, and in addition to learning, c-fos is also activated, although to a lesser extent, in the control groups that are submitted to the task without learning (Bertaina and Destrade 1995; Hess et al. 1995) as well as in response to sensorimotor input, arousal, or stress (Hughes and Dragunow 1995) and general cell activity that occurs during learning or exploration (e.g., see Handa et al. 1993; Zhu et al. 1995, 1996). In our experiments, we found no discernible change in syntaxin $1 \mathrm{~B}$ expression in the motor or parietal cortices and negligible changes in animals of the motor control group that were submitted to a similar sensory and motor experience. The gene encoding syntaxin is regulated by the induction of LTP and is specific to LTP as it

$$
\begin{array}{lllllllllllllll}
L & E & A & R & N & I & N & G & \begin{array}{c}
\boldsymbol{Q} \\
385
\end{array} & M & E & M & O & R & Y
\end{array}
$$




\section{Davis et al.}

Figure 7: The relationship between learning in the reference memory task and expression of syntaxin $1 \mathrm{~B}$ in the hippocampus $(A, B)$ and in the prelimbic area of the prefrontal cortex $(C, D)$. In the hippocampus, when rats were between 0 and $60 \%$ of their maximum performance, there was no change in the expression of syntaxin $1 \mathrm{~B}$, but, when they had attained $>60 \%$ of the learning performance there was a trend towards a linear increase in the levels of expression of syntaxin until rats had reached their maximum level of performance $(A)$, however this correlation failed to reach a level of significance. There was no correlation between syntaxin expression and rats' ability to learn $(B)$. In the prefrontal cortex there was a strong linear correlation between syntaxin 1B expression and performance. The correlation was much sharper than that observed in the hippocampus. Rats did not start to show an increase in the expression of syntaxin until they had reached $>70 \%$ of their maximum learning performance $(C)$. In contrast to the hippocampus, there was also a correlation between the level of expression of syntaxin in the prefrontal cortex and the ability of rats to learn the task (D). Correlations are based on the values of syntaxin expression from individual rats, normalized to the naive controls.
A

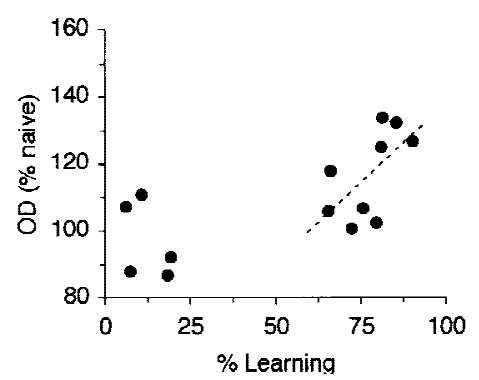

C

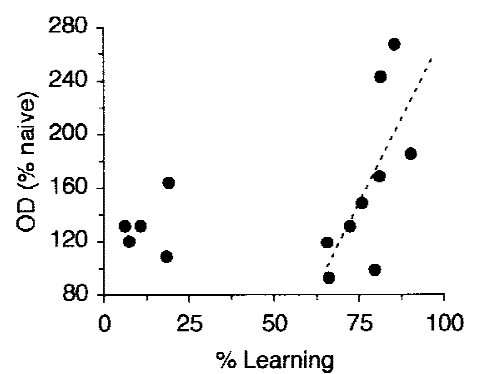

B

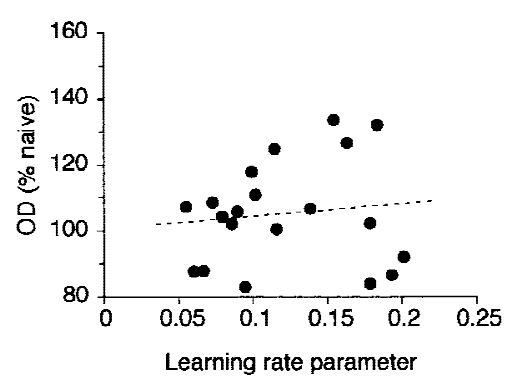

D

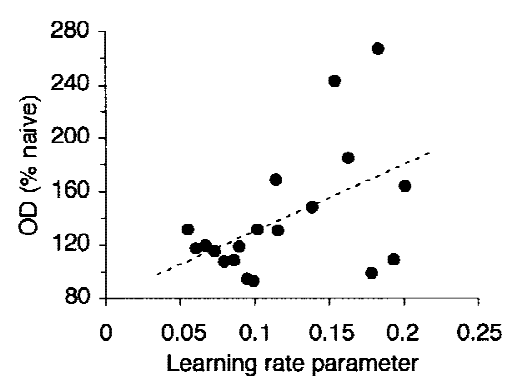

is not upregulated if LTP is blocked by an NMDAreceptor antagonist (Hicks et al. 1997). The increase in the expression of syntaxin $1 \mathrm{~B}$ in learning is thus a further argument to suggest that LTP-like mechanisms occur during learning. We have established that regulation in the expression of syntaxin is a strong candidate mechanism for mediating trans-synaptic plasticity in the hippocampal circuitry (Hicks et al. 1997) and the upregulation of the gene leads to an increase in protein content and in the potential for the release of glutamate at the next synaptic connection, downstream from the site of LTP induction (Helme-Guizon et al. 1998). As it has been demonstrated that glutamate release is increased following the induction of LTP in the dentate gyrus (Dolphin et al. 1982; Bliss and Collingridge 1993) and in both the dentate gyrus and the CA regions of the hippocampus after learning (Laroche et al. 1987, 1990a; Richter-Levin et al. 1995), these data suggest that regulation of syntaxin expression may contribute to the learningdependent increase in the capacity of hippocampal synapses to release glutamate and hence may at least in part underlie changes in synaptic function during learning.
In terms of what aspects of learning syntaxin may be implicated in, we have described how it is correlated strongly with the actual learning performance, both in the hippocampus during working memory and in the hippocampus and the prelimbic area of the prefrontal cortex during the reference memory task. However, we also found a trend towards a correlation between the levels of expression of syntaxin and the ability to learn. The ability of rats to learn the task, or in other words whether they are fast or slow learners, was determined from the learning rate parameter. By correlating this parameter with changes in syntaxin expression, we found that fast learners, regardless of whether they were learning a working or a reference memory task, show a higher level of learninginduced increase in expression in the prefrontal cortex. In contrast, such a trend was not found in the hippocampus. This indicates that better learners may have a greater potential for regulation of syntaxin in the prefrontal cortex, a hypothesis that would require further experimental testing.

A related question concerns how syntaxin may be involved in the processing of information necessary for learning, and, as a marker of trans-syn- 
aptic plasticity, whether the increase in syntaxin expression in the hippocampus and the prefrontal cortex may somehow reflect the transfer of information from one structure to the other after a period of consolidation during the reference memory task. Although in general it appears that syntaxin $1 \mathrm{~B}$ expression is increased in the prefrontal cortex during the reference memory task and in the hippocampus during a working memory task, it is not a simple dissociation, as there is some form of interaction between the two structures during the reference memory task. This is indicated strongly by the concomitant increase in both structures and the very high individual correlation in the changes observed in hippocampal and prefronto-cortical structures in the reference memory task. Theoretical and experimental evidence suggest that hippocampal and neocortical networks form a unique functional memory system in which a critical role for the hippocampus has been postulated in directing and organizing cortical representations (Wickelgren 1979; Teyler and DiScenna 1986; Damasio 1989; Mishkin 1990; Squire and Alvarez 1995). Particular emphasis in this context has been placed in hippocampo-prefrontal interactions (Goldman-Rakic 1987; Miller 1991; Doyère et al. 1993). In the reference memory task, although no time-dependent relation in the increased levels of syntaxin $1 \mathrm{~B}$ expression was observed between the hippocampus and the prefrontal cortex, there was a synchronized correlation in the expression levels of syntaxin in the two regions during the critical period of learning that strongly reinforces the suggestion that the two structures work in concert and may bind into a functional unit (see Wickelgren 1979) at a specific phase of learning.

In summary, these data are consistent with the type of dynamics that may be expected from learning-induced trans-synaptic plasticity within neural networks during different spatial learning tasks. Most importantly, they show that syntaxin is implicated in learning either a reference or a working memory task, at a critical point in learning, and establish that there is a strong correlation between the increase in syntaxin $1 \mathrm{~B}$ expression and performance in these tasks. During the learning of a reference memory task, there is activation within a widespread network that includes the hippocampus and at least the prelimbic region of the prefrontal cortex, and as shown previously, areas of the nucleus accumbens (Davis et al. 1996), whereas in the working memory task this network is more restricted to the hippocampus, although we cannot dismiss the possibility that other structures, including the septo-hippocampal circuit, may be involved. As a mechanism involved in transsynaptic plasticity, it is our hypothesis that regulation of syntaxin expression plays a role in stabilizing a memory trace within these networks or cell assemblies. The establishment of this form of synaptic modification would thus render the network readily available to be activated by a much reduced level or more sparsely distributed input. Although it will be important in further experiments to examine the time-course of expression of the protein during learning, the mechanism described here at the mRNA level does not indicate a long-lasting, stable change such as the increase in spine density (Moser at al. 1994) or rearrangement of synaptic connections (Rusakov et al. 1997) observed several days after learning, but a temporarily restricted mechanism more likely to be implicated in the learning process itself. This does not rule out the possibility that this is one of the potential molecular mechanisms necessary for the formation of new synapses or for stabilizing changes in existing synapses. This being the case, our results show that the initiation of this process is associated closely with the progress of learning. We suggest that recurring firing patterns of connected cells are stabilized progressively during learning via a mechanism of trans-synaptic plasticity acting to configure a specific distributed circuit encoding the memory trace. Although the general idea that memory is encoded in distributed patterns of modified connections within widespread circuits is accepted widely, there are two conceptually different views of how cellular changes may occur all along a network of connected neurons. The first view holds that synaptic plasticity would occur almost independently at each step in the network, mostly relying on whether a certain coactivation threshold is reached. A contrasting view, however, would require a level of dependence in which the induction of a synaptic change at one point in the network would in itself be instrumental in-or promote-the induction of synaptic changes downstream from it. Our results on the involvement of the regulation of syntaxin expression in trans-synaptic plasticity together with the present findings in learning favor the second view, suggesting that the occurrence of plasticity at the input stage of the hippocampus contributes directly to the induction of changes downstream in hippocampal circuitry during the learning of spatial working and reference memory tasks, and in more widespread

$$
\begin{array}{lllllllllllllll}
L & E & A & R & N & I & N & G & \underset{387}{\mathbf{Z}} & M & E & M & O & R & Y
\end{array}
$$




\section{Davis et al.}

\section{hippocampo-cortical networks during reference memory.}

\section{Acknowledgments}

The publcation costs of this article were defrayed in part by payment of page charges. This article must therefore be hereby marked "advertisement" in accordance with 18 USC section 1734 solely to indicate this fact.

\section{References}

Bank, B., A. Deweer, A.M. Kuzirian, H. Rasmussen, and D.L. Alkon. 1988. Classical conditioning induces long-term translocation of protein kinase $\mathrm{C}$ in the rabbit hippocampal CA1 cells. Proc. Natl. Acad. Sci. 85: 1988-1992.

Beck, C.H.M. and H.C. Fibiger. 1995. Conditioned fear-induced changes in behaviour and in the expression of the immediate early gene c-fos: With and without diazepam pretreatment. J. Neurosci. 15: 709-720.

Bennett, M.K., N. Calakos, and R.H. Scheller 1992. Syntaxin: A synaptic protein implicated in docking of synaptic vesicles at presynaptic active zones. Science 257: 255-259.

Bertraina, V. and C. Destrade. 1995. Differential time course of c-fos mRNA expression in hippocampal subfields following acquisition and recall testing in mice. Cog. Brain Res. 2: 269-275.

Bliss, T.V.P. and T. Lomo. 1973. Long-lasting potentiation of synaptic transmission in the dentate area of the anaesthetised rabbit following stimulation of the perforant path. J. Physiol. (London) 232: 331-356.

Bliss, T.V.P. and G.L. Collingridge. 1993. A synaptic model of memory: long-term potentiation in the hippocampus. Nature 361: 31-39.

Bliss, T.V.P. and A.R. Gardner-Medwin. 1973. Long-lasting potentiation of synaptic transmission of the dentate area of the unanaesthetized rabbit following stimulation of the perforant path. J. Physiol. (London) 232: 357-374.

Bloch, V. and S. Laroche. 1984. Facts and hypotheses related to the search for the engram. In Neurobiology of learning and memory (ed. G. Lynch, J.L. McGaugh, and N.M. Weinberer), pp. 249-260. Guildford Press, New York, NY.

Broadie, K., A. Prokop, H.J. Bellen, C.J. O'Kane, K.L. Schultz, and S.T. Sweeny. 1995. Syntaxin and synaptobrevin function downstream of vesicle docking in Drosophila. Neuron 15: 663-673.

Chapman, E.R., P.I. Hanson, S. An, and R. Jahr. 1955. Ca2+ regulates the interaction between synaptotagmin and syntaxin 1. J. Biol. Chem. 270: 23667-23671.

Chrobak, J.J. and G. Buzsáki. 1996. Entorhinal-hippocampal network dynamics constrain synaptic potentiation and memory formation. In Long-term potentiation: Current issues (ed. M. Baudry and J.L. Davies), pp. 215-232. MIT Press, Cambridge, MA.

Cole, A.J., D.W. Saffen, J.M. Baraban, and P.F. Worley. 1989. Rapid increase of an immediate early gene messenger RNA in hippocampal neurons by synaptic NMDA receptor activation. Nature 340: 474-476.

Damasio, A.R. 1989. Time-locked multiregional retroactivation: A system-level proposal for the neural substrates of recall and recognition. Cognition 33: 25-62.

Davis, S. and S. Laroche. 1998. A molecular biological approach to synaptic plasticity and learning. C. R. Acad. Sci. 321: 97-107.

Davis, S., J. Rodger, A. Hicks, J. Mallet, and S. Laroche. 1996. Brain structure and task-specific increase in expression of the gene encoding syntaxin $1 \mathrm{~B}$ during learning in the rat: A potential molecular marker for learning-induced synaptic plasticity in neural networks. Eur. J. Neurosci. 8: 2068-2074.

Deadwyler, S.A., T. Bunn, and R.E. Hampson. 1996. Hippocampal ensemble activity during spatial delayed-nonmatch-to-sample performance in rats. J. Neurosci. 16: 354-372.

Desmond, N.L. and W.B. Levy. 1990. Morphological correlates of long-term potentiation imply the modification of existing synapses, not synaptogenesis, in the hippocampal dentate gyrus. Synapse 5: 139-143.

Dolphin, A., M.L. Errington, and T.V.P. Bliss. 1982. Long-term potentiation of the perforant path in vivo is associated with increased glutamate release. Nature 297: 496-498.

Doyère, V., F. Burette, C. Redini-Del Negro, and C. Laroche. 1993. Long-term potentiation of hippocampal afferents and efferents to prefrontal cortex: Implications for associative learning. Neuropsychologia 31: 1031-1053.

Edwards, F.A. 1995. LTP: A structural model to explain the inconsistencies. Trends Neurosci. 18: 365-369.

Frey, U. and R.G.M. Morris. 1997. Synaptic tagging and long-term potentiation. Nature 385: 533-536.

Fordyce, D.E., R.V. Bhat, J.M. Braban, and J.M. Wehner. 1994. Genetic and activity-dependent regulation of zif-268 expression: Association with spatial learning. Hippocampus 4: $559-568$.

Goldman-Rakic, P.S. 1987. Circuitry of primate prefrontal cortex and regulation of behavior by representational memory. In Handbook of physiology, vol. 4: The nervous system (ed. S. Plum), pp. 373-417. American Physiological Society, Bethesda, MD.

Handa, R.J., K.M. Nunley, and M.R. Bollnow. 1993. Induction of c-fos mRNA in the brain and anterior pituitary gland by an novel environment. NeuroReport 4: 1079-1082.

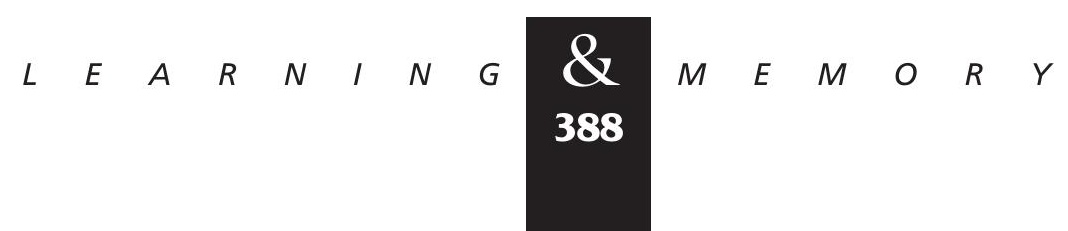


Hebb, D.O. 1949. The organization of behaviour. Wiley, New York, NY.

Helme-Guizon, A., S. Davis, M. Israel, B. Lesbats, J. Mallet, S. Laroche, and A. Hick. 1998. Increase in syntaxin 1B and glutamate release in mossy fibre terminals following the induction of LTP in the dentate gyrus: A candidate molecular mechanism underlying transsynaptic plasticity. Eur. J. Neurosci. 10: 2231-2237.

Hess, U.S., G. Lynch, and C.M. Gall. 1995. Changes in c-fos mRNA expression in rat brain during odor discrimination learning: Differential involvement of hippocampal subfields, CA1 and CA3. J. Neurosci. 15: 4786-4795.

Hess, U.S., C.M. Gall, R. Granger, and G. Lynch. 1997. Differential patterns of c-fos mRNA expression in amygdala during successive stages of odor discrimination learning. Learn. \& Mem. 4: 262-283.

Hicks, A., S. Davis, A. Helme-Guizon, S. Laroche, and J. Mallet. 1997. Synapsin I and Syntaxin 1B: Key elements in the control of neurotransmitter release are regulated by neuronal activation and long-term potentiation in vivo. Neuroscience 79: 329-340.

Hughes, P. and M. Dragunow. 1995. Induction of immediate-early genes and the control of neurotransmitter-regulated gene expression with the nervous system. Pharmacol. Rev. 47: 133-178.

Isaacs, J.T.R., R.A. Nicholl, and R.C. Malenka. 1995. Evidence for silent synapses: Implications for the expression of LTP. Neuron 15: 427-434.

Jay, T.M. and M.P. Witter. 1991. Distribution of the hippocampal CA1 and subicular efferents in the prefrontal cortex of the rat: A study using anterograde transport of Phaseolus vulgaris leucoagglutinin. J. Comp. Neurol. 313: 574-586.

Jay, T.M., F. Burette, and S. Laroche. 1995. NMDA receptor-dependent long-term potentiation in the hippocampal afferent fibre system to the prefrontal cortex. Eur. J. Neurosci. 7: 247-250.

Konorski, J. 1948. Conditioned reflexes and neuron organisation. Cambridge University Press, Cambridge, UK.

Kreiter, A.K. and W. Singer. 1996. Stimulus-dependent synchronization of neuronal responses in the visual cortex of the awake macaque monkey. J. Neurosci. 16: 2381-2396.

Laroche, S., M.L. Errington, M.A. Lynch, and T.V.P. Bliss. 1987. Increase in $\left[{ }^{3} \mathrm{H}\right]$ glutamate release from slices of dentate gyrus and hippocampus following classical conditioning in the rat. Behav. Brain Res. 25: 23-29.

Laroche, S., C. Redini-Del Negro, M.P. Clements, and M.A. Lynch. 1990a. Long-term activation of phosphoinositide turnover associated with increased release of amino acids in the dentate gyrus and hippocampus following classical conditioning in the rat. Eur. J. Neurosci. 2: 534-543.
Laroche, S., T.M. Jay, and A-M. Thierry. 1990b. Long-term potentiation in the prefrontal cortex following stimulation of the hippocampal CA1/subicular region. Neurosci. Lett. 114: $184-190$.

Li, L., L-S. Chin, O. Shupliakov, L. Brodin, T.S. Sihra, O. Hvalby, V. Jensen, D. Zheng, J.O. McNamara, P. Greengard, and P. Andersen 1995. Impairment of synaptic vesicle clustering and of synaptic transmission, and increased seizure propensity, in synapsin I-deficient mice. Proc. Natl. Acad. Sci. 92: 9235-9239.

McNaughton, B.L. and R.G.M. Morris. 1987. Hippocampal synaptic enhancement and information storage within a distributed memory system. Trends Neurosci. 10: 408-415.

Miller, R. 1991. Cortico-hippocampal interplay and the representation of contexts in the brain. Springer-Verlag, Berlin, Germany.

Mishkin, M. 1990. Vision, memory, and the temporal lobe: Summary and perspectives. In Vision, memory, and the temporal lobe. pp. 427-436. Elsevier, Amsterdam, The Netherlands.

Moser, M.B., M. Trommald, and P. Andersen. 1994. An increase in dendritic spine density on hippocampal CA1 pyramidal cells following spatial-learning in adult rats suggests the formation of new synapses. Proc. Natl. Acad. Sci. 91: 12673-12675.

Mulder, AB., M.P.M. Arts, and F.H. Lopes da Silva. 1993. Long-term potentiation simultaneously elicited in: Hippocampus, nucleus accumbens and prefrontal cortex. Neurosci. Res. Comm. 13: S11-S14.

Murthy, V.N. and E.E. Fetz. 1996. Synchronization of neurons during local field potential oscillations in sensorimotor cortex of awake monkeys. J. Neurophysiol. 76: $3968-3982$.

Nguyen, P.V., T. Abel, and E.R. Kandel. 1994. Requirement of a critical period of transcription for induction of a late phase of LTP. Science 265: 1104-1107.

Nicolelis, M.A., L.A. Baccala, R.C.S. Lin, and J.K. Chapin. 1995. Sensorimotor encoding by synchronous neural ensemble activity at multiple levels of the somatosensory system. Science 268: 1353-1358.

Nogués, X., J. Micheau, and R. Jaffard. 1994. Protein kinase $C$ activity in the hippocampus following spatial learning tasks in mice. Hippocampus 4: 71-78.

Olds, J., J.F. Disterhoft, M. Segal, C.L. Kornbluff, and R. Hirsch. 1972. Learning centres of rat brain mapped by measuring latencies of conditioned unit responses. J. Neurophysiol. 35: 202-219.

Olds, J.L., M.L. Anderson, D.L. McPhie, L.D. Staten, and D.L. Alkon. 1989. Imagining of memory-specific changes in the distribution of protein kinase $\mathrm{C}$ in the hippocampus. Science 245: 866-869.

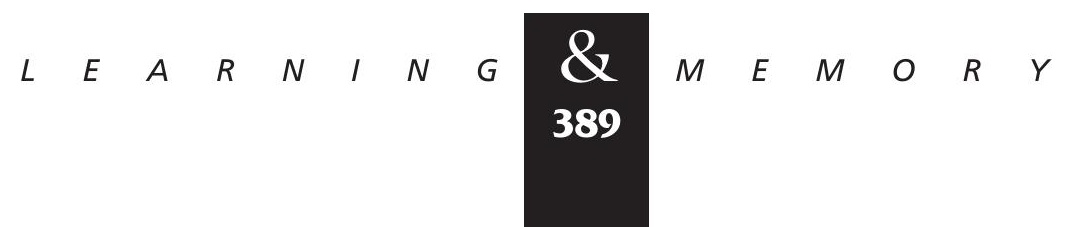




\section{Davis et al.}

Otani, S., C.J. Marshall, W.P. Tate, G.V. Goddard, and W.C. Abraham. 1989. Maintenance of LTP in the rat dentate gyrus requires protein synthesis but not mRNA synthesis

immediately post-tetanization. Neuroscience 28: 519-526.

Qian, Z., M.E. Gilbert, M.A. Colicos, E.R. Kandel, and D. Kuhl. 1993. Tissue-plasminogen activator is induced as an immediate-early gene during seizure, kindling and long-term potentiation. Nature 361: 453-457.

Richter-Levin, G., L. Canevari, and T.V.P. Bliss. 1995. Long-term potentiation and glutamate release in the dentate gyrus: Links to spatial learning. Behav. Brain Res. 66: 37-40.

Rusakov, D.A., H.A. Davies, E. Harrison, G. Diana, G. Richter-Levin, T.V.P. Bliss, and M.G. Stewart. 1997. Ultrastructural synaptic correlates of spatial learning in rat hippocampus. Neuroscience 80: 69-77.

Sirevaag, A.M. and W.T. Greenough. 1988. A multivariate statistical summary of synaptic plasticity measures in rats exposed to complex, social and individual environments. Brain Res. 441: 386-392.

Smirnova, T., S. Laroche, M.L. Errington, A.A. Hicks, T.V.P. Bliss, and J. Mallet. 1993. Transsynaptic expression of a presynaptic glutamate receptor during hippocampal long-term potentiation. Science 262: 433-436.

Squire, L.R. and P. Alvarez. 1995. Retrograde amnesia and memory consolidation: A neurobiological perspective. Curr. Opin. Neurobiol. 5: 169-177.

Südhof, T.C. 1995. The synaptic vesicle cycle: A cascade of protein-protein interactions. Nature 375: 645-653.

Teyler, T.J. and P. DiScenna. 1986. The hippocampal memory indexing theory. Behav. Neurosci. 100: 147-154.

Thomas, K.L., S. Laroche, M.L. Errington, T.V.P. Bliss, and S.P. Hunt. 1994a. Spatial and temporal changes in signal transduction pathways during LTP. Neuron 13: 737-745.

Thomas, K.L., S. Davis, S. Laroche, and S.P. Hunt. 1994b. Regulation in the expression of NR1 NMDA glutamate receptor subunits during hippocampal LTP. NeuroReport 6: 119-123.

Thomas, K.L., S. Davis, S.P. Hunt, and S. Laroche. 1996. Alterations in the expression of specific glutamate receptor subunits following hippocampal LTP in vivo. Learn. \& Mem. 3: 197-208.

Tischmeyer, W., L. Kaczmarek, M. Strauss, R. Jork, and H. Matthies. 1990. Accumulation of c-fos mRNA in rat hippocampus during acquisition of a brightness discrimination. Behav. Neural Biol. 54: 165-171.

Tocco, G., K.K. Devgan, S.A. Hauge, C. Weiss, M. Baudry, and R.F. Thompson. 1991. Classical conditioning selectively increases AMPA/quisqualate receptor binding in rabbit hippocampus. Brain Res. 359: 638-641.
Van Harrenveld, A. and E. Fifkova. 1975. Swelling of dendritic spines in the fascia dentata after stimulation of the perforant path fibres as a mechanism of post tetanic potentiation. Exp. Neurol. 49: 736-749.

Wickelgren, W.A. 1979. Chunking and consolidation: A theoretical synthesis of semantic networks configuring in conditioning, S R versus cognitive learning, normal forgetting, the amnesic syndrome and the hippocampal arousal system. Psychol. Rev. 86: 44-60.

Wilson, M.A. and B.L McNaughton. 1993. Dynamics of the hippocampal ensemble code for space. Science 261: 1055-1058.

Wisden, W., M.L. Errington, S. Williams, S.B. Dunnett, C. Waters, D. Hitchcock, G. Evans, T.V.P. Bliss, and S.P. Hunt. 1990. Differential expression of immediate early genes in the hippocampus and spinal cord. Neuron 4: 603-614.

Yeckel, M.F. and T.W. Berger. 1990. Feedforward excitation of the hippocampus by afferents from the entorhinal cortex: Redefinition of the role of the trisynaptic pathway. Proc. Natl. Acad. Sci. 87: 5832-5836.

Zhu, X-O., M.W. Brown, B.J. McCabe, and J.P. Aggleton. 1995. Effects of the novelty or familiarity of visual stimuli on the expression of the immediate early gene c-fos in the rat brain. Neuroscience 69: 821-829.

Zhu, X-O., B.J. McCabe, J.P. Aggleton, and M.W. Brown. 1996. Mapping visual recognition memory through expression of the immediate early gene c-fos. NeuroReport 7: 1871-1875.

Received March 19, 1998; accepted in revised form July 17, 1998.

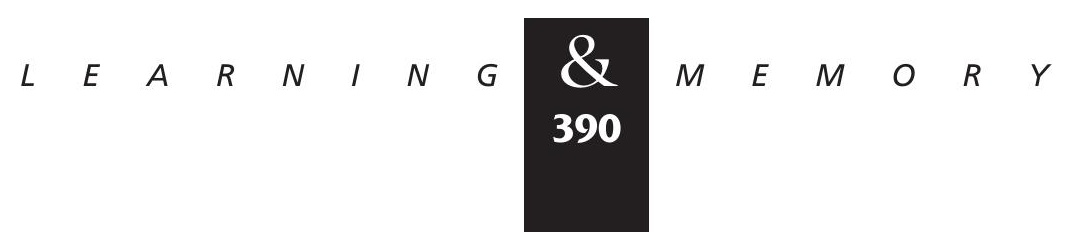




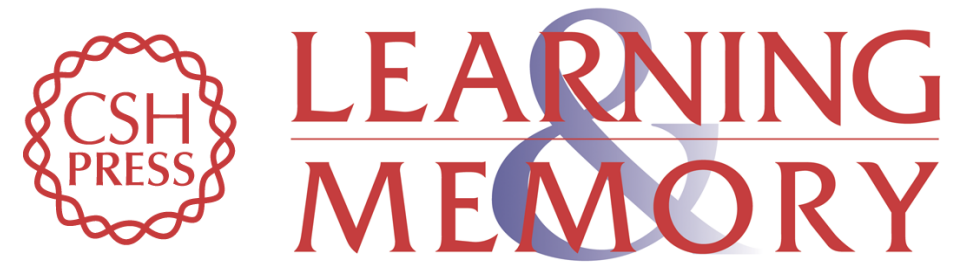

\section{Increase in Syntaxin 1B mRNA in Hippocampal and Cortical Circuits During Spatial Learning Reflects a Mechanism of Trans-synaptic Plasticity Involved in Establishing a Memory Trace}

Sabrina Davis, Jennifer Rodger, Aline Stéphan, et al.

Learn. Mem. 1998, 5:

Access the most recent version at doi:10.1101//m.5.4.375

References This article cites 64 articles, 17 of which can be accessed free at: http://learnmem.cshlp.org/content/5/4/375.full.html\#ref-list-1

License

Email Alerting Receive free email alerts when new articles cite this article - sign up in the box at the Service top right corner of the article or click here. 